\title{
Trisomy G-22 and a Chromosome Mode 44 in the Multiple Myeloma
}

\author{
S. M. Handa and Manjit Kaur ${ }^{1}$ \\ Department of Zoology, Panjab University, Chandigarh-160014, India
}

Accepted April 25, 1985

Chromosomal abnormalities have recently been reported in a variety of haematological disorders such as the acute leukaemia, the chronic myeloid leukaemia and the chronic familial lymphatic myeloma etc. (Awano and Tsuda 1960, Bottura et al. 1961, German et al. 1961, Benirschke et al. 1962, Pfeiffer et al. 1962, Castoldi et al. 1963, Elves and Israels 1963, Lewis et al. 1963, Gahrton et al. 1977, Olinici et al. 1978, Kelsen et al. 1979, Hagemeijer et al. 1961).

Previous studies have shown a clear modal number of 44 chromosomes in a case of plasmacytoma, chraracterized by a variety of the chromosome rearrangements (Castoldi et al. 1963). Two distinct chromosome patterns have been reported in a case of myelometosis-one with the normal 46 chromosomes and the other with abnormal number of chromosomes ranging from 50-56. These cell lines differ morphologically from the normal human chromosome pattern in the sense that they have the chromosomes which are thicker fuzzy in out line and difficult to analyse (Lewis et al. 1963).

Some new karyotypic abnormalities in a case of the multiple myeloma were detected by Dosik and Verma (1980). The large unusual marker chromosomes were seen by them in association with multiple myeloma i.e. chromosomes 1 and $14 \mathrm{q}^{+}$. The karyotype was described as $44, \mathrm{XO},-1,-2,-8,-11,-13,-14$, $-16,-17,-20,-\mathrm{X},+\mathrm{t}(1 \mathrm{q} ; 14 \mathrm{q}),+\mathrm{i}(2 \mathrm{q}),+\mathrm{t}(8 \mathrm{q} ; 11 \mathrm{p}),+\mathrm{i}(16 \mathrm{p})$ and $\mathrm{i}(16 \mathrm{q})$, $+\operatorname{rec}(17),+\operatorname{rec}(20),+21$. Wurster-Hill et al. (1978), Liang and Rowley (1978) opined that the modal number is usually in the hypodiploid range. Chromosomal abnormalities in patients with the multiple myeloma appear to be highly variable. A $14 \mathrm{q}^{+}$marker has also been reported by them in patients with the multiple myeloma or the plasma cell leukaemia.

In the present study, a case of the multiple myeloma has been dealt with in full details with the help of a number of karyotypes. It appears that the range of chromosome number is from $40-45$ with trisomy G-22 in this malignant tissue. The modal number, however, is 44 quite in conformity with that described by Castoldi et al. (1963).

\section{Materials and methods}

Bone marrow for the chromosomal analysis was aspirated from the amputated

1 The authors dedicate this paper to Prof. G. P. Sharma, F. N. A., formerly Head of the Department of Zoology, Panjab University, Chandigarh, in view of his valuable contributions to studies on cytogenetics. 

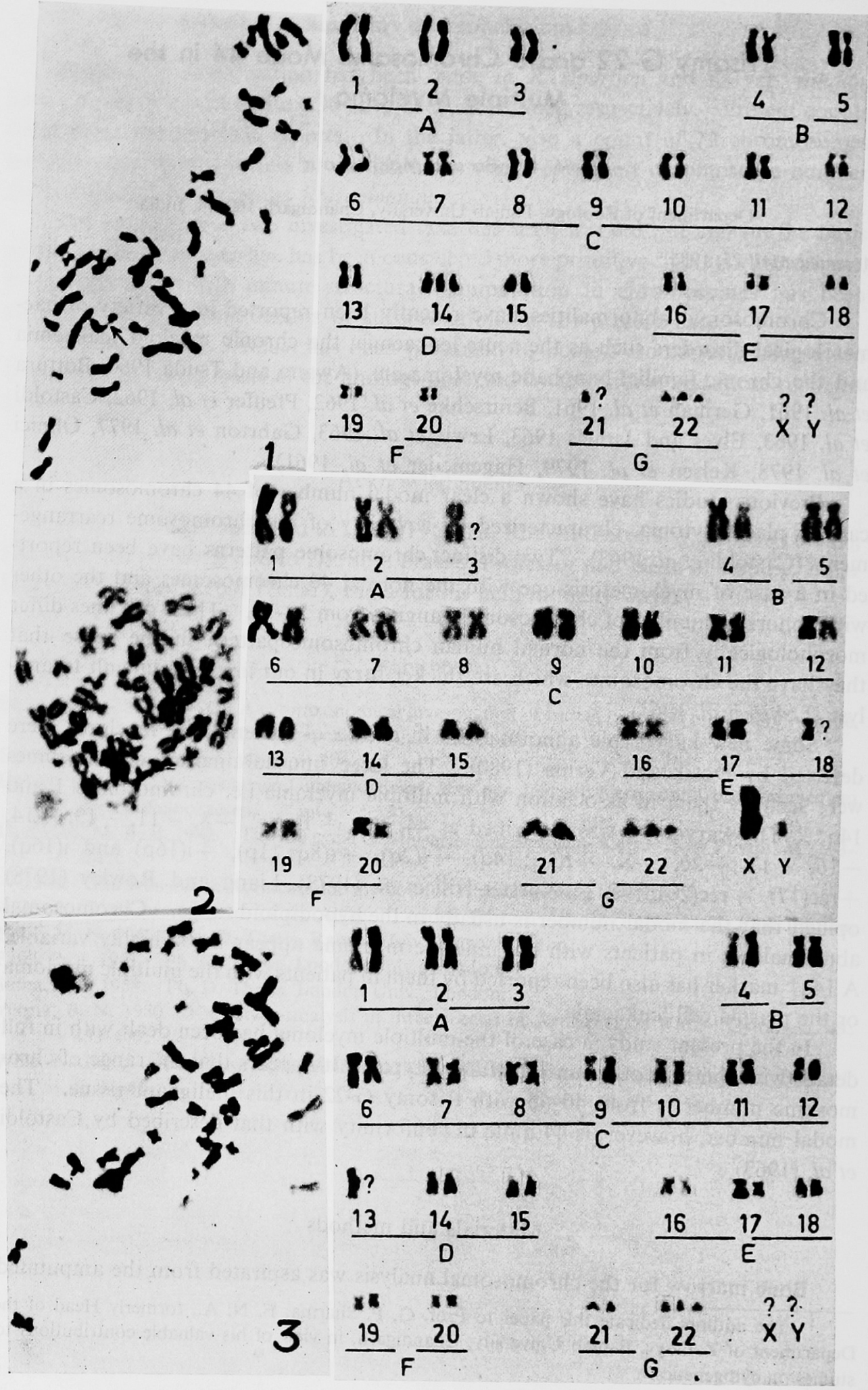
leg of the patient immediately after its amputation at Frances Newton hospital, Firozpur (Cr. No. UN 919573). The marrow was transferred to medium TC-199 containing $1 \mu \mathrm{g} / \mathrm{ml}$ of colchicine, using sterile techniques and incubated for $2 \mathrm{hr}$. The cells in mitosis were harvested by the method proposed by Hamerton (1971). Slides were flame dried and stained in $4 \%$ Giemsa stain for $10 \mathrm{~min}$ (Gurr 1962).

Results and discussion

Trisomy G-22 is the most common feature observed in almost all the cells

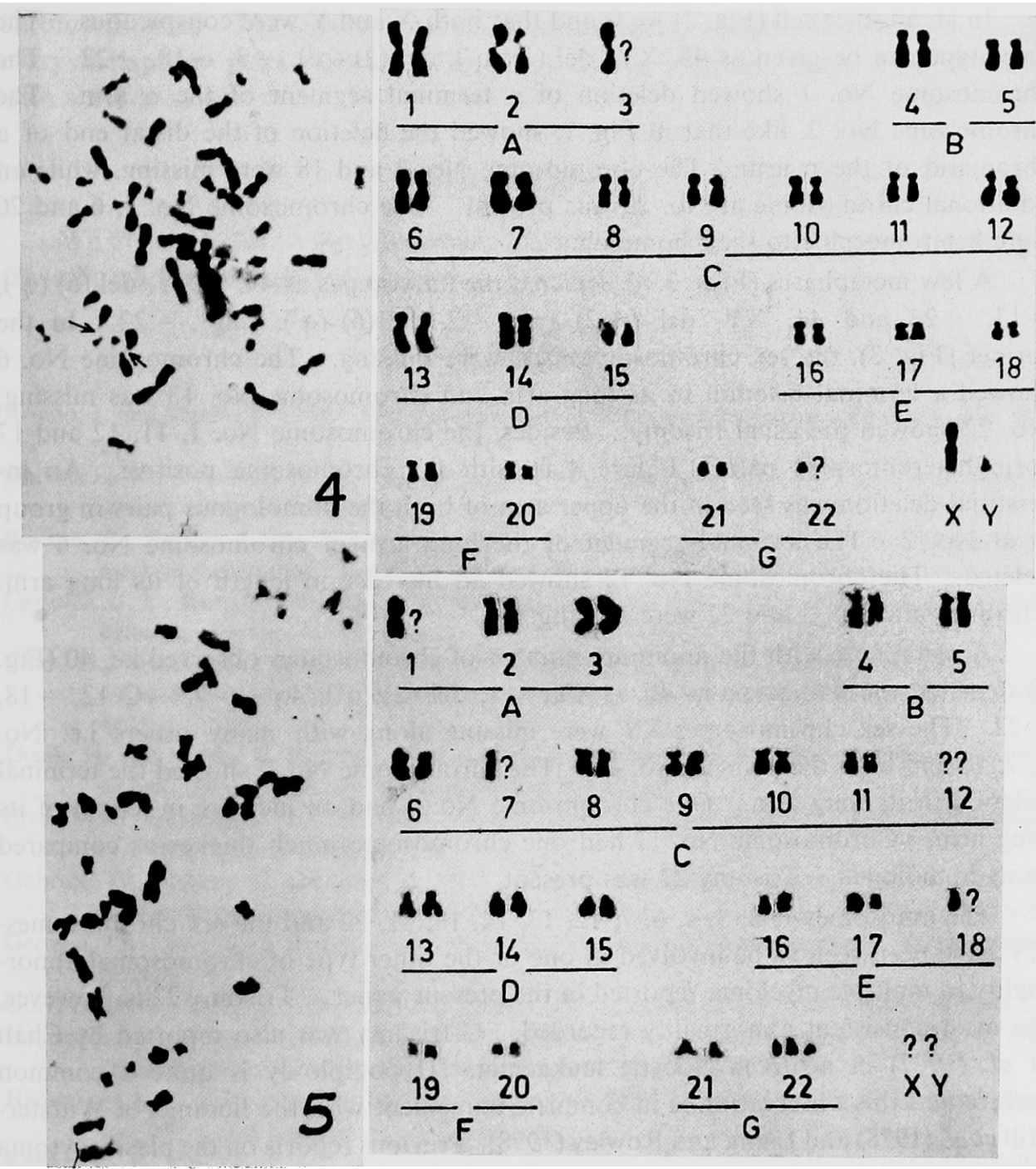

Figs. 4-5. Multiple myeloma. 4, metaphase and karyotype, $2 n=44, X Y$ present. 5 , metaphase and karyotype, $2 \mathrm{n}=40, \mathrm{XY}$ missing, trisomy $\mathrm{G}_{22} . \times 1200$

Figs. 1-3. Multiple myeloma. 1, metaphase plate and a karyotype, $2 \mathrm{n}=45, \mathrm{XY}$ missing, trisomy $G_{22}$. 2, metaphase and karyotype, $2 n=45, X Y$ present, trisomy $G_{22}$. 3, metaphase and karyotype, $2 n=44, X Y$ missing, trisomy $G_{22} . \times 1200$ 
studied. About 40 distinct metaphase plates were observed. The chromosomes ranged from 40 to 45 with a mode at 44 .

In one of the cells with 45 chromosomes (Fig. 1), the sex chromosomes could not be found. The karyotype can be given as $45,-\mathrm{XY}$; del (2) (p?), del (6) (p?), $+14,-21,+22$. A segment of the upper arm of one homologue of the chromosome No. 2 appeared deleted, one chromosome at No. 5 was not with a similar thickness/thinness as of its homologue. Chromosome No. 6 showed an interstitial deletion right above the centromere in its $\mathrm{p}$ arm. Besides, the chromosome No. 21 was missing. The chromosome No. 14 and 22 showed trisomy.

In an another cell (Fig. 2) we found that both $X$ and $Y$ were conspicuous. The karyotype can be given as $45, \mathrm{XY}$; $\operatorname{del}(1)\left(\mathrm{q}^{?}\right)$, del (2) $\left(\mathrm{p}^{?}\right),-3,-18,+22$. The chromosome No. 1 showed deletion of a terminal segment of the $q$ arm. The chromosome No. 2, like that in Fig. 1, showed the deletion of the distal end of a chromatid of the p arm. The chromosome No. 3 and 18 were missing, while an additional chromosome at No. 22 was present. The chromosome No. 4, 6 and 20 were heteromorphic to their homologues.

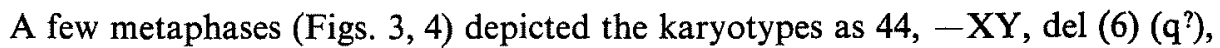
$-13,+22$ and $44, \mathrm{XY}$, del (A 2) (p?), -3, del (6) $\left(\mathrm{q}^{?}\right), 12 \mathrm{q}^{+},-22$. In the former (Fig. 3), the sex chromosomes-XY were missing. The chromosome No. 6 showed a terminal deletion in its long arm and chromosome No. 13 was missing. No. 22 showed the usual trisomy. Besides, the chromosome No. 1, 11, 12 and 17 form heteromorphic pairs. Figure 4 is with sex chromosome positive. An interstitial deletion was seen in the upper arm of both the homologous pairs in group A at No. 2. The terminal segment of the long arm of chromosome No. 6 was deleted. The chromosome No. 12 showed an increase in length of its long arm. Chromosome No. 3 and 22 were missing.

A metaphase with the minimum number of chromosomes observed i.e. 40 (Fig. 5) depicted the karyotype as $40,-\mathrm{XY},-1$, del (2) $\left(\mathrm{q}^{?}\right), 4 \mathrm{q}^{+},-7,-\mathrm{C} 12,-18$, +22 . The sex chromosomes-XY were missing along with many others i.e. No. 1, 7, 18 and both the pairs at No. 12. The chromosome No. 2 showed the terminal deletion in its long arm. One chromosome No. 4 had an increase in length of its long arm. Chromosome No. 17 had one chromosome much thicker as compared to its homologue. Trisomy 22 was present.

The autosomes $1,2,3,4,6,7,12,13,14,18,21,22$ and the sex chromosomes$\mathrm{XY}$ have been seen to be involved in one or the other type of chromosomal abnormality in multiple myeloma reported in the present paper. Trisomy 22 is, however, the most consistent abnormality recorded. G-trisomy was also reported by Chan et al. (1977) in acute myelocytic leukaemia. Hypodiploidy is quite a common feature and this observation is in complete agreement with the findings of WursterHill et al. (1978) and Liang and Rowley (1978). Previous reports on the plasmacytoma and the multiple myeloma (Castoldi et al. 1963, Dosik and Verma 1980) also confirmed the modal number of 44 chromosomes as observed in the present investigation. The abnormally large marker chromosomes 1 and $14 \mathrm{q}^{+}$, as reported by Wurster-Hill et al. (1978) and Liang and Rowley (1978) were, however, not observed. The studies indicate that the presence of a complex chromosomal abnormality is a 
common observation in all multiple myelomas (Dosik and Verma 1980). The chromosomal abnormalities observed during the present study are certainly the reminiscent of the chromosomal imbalance often associated with malignant growth.

\section{Summary}

In the multiple myeloma, the autosomes No. $1,2,3,4,6,7,12,13,14,18,21$, 22 and sex chromosomes-XY are most commonly involved in one or the other type of abnormalities, such as deletions, interstitial deletion, translocation, missing of chromomsomes. The trisomy 22 is the most consistent abnormality found in almost every metaphase plate studied. The chromosome numbers range from 40 to 45 with a mode at 44 .

\section{Acknowledgements}

We are thankful to the Chairman, Department of Zoology, Panjab University, Chandigarh for providing the laboratory facilities.

\section{References}

Awano, I. and Tsuda, F. 1960. The chromosomes of human marrow cells. Cytologia 26: 305312.

Benirschke, K., Brownhill, L. and Ebough, F. G. 1962. Chromosomal abnormalities in Waldenstrom's macroglobulinaemia. Lancet 1: 594-595.

Bottura, C., Ferrari, I. and Veiga, A. A. 1961. Chromosome abnormalities in Waldenstrom's macroglobulinaemia. Lancet 1: 1170.

Castoldi, G. L., Ricci, N., Punturieri, E. and Bosi, L. 1963. Chromosomal imbalance in plasmacytoma. Lancet 1: 829.

Chan, H., Michael, A., Barth, H., Mammo, A. and Peter, H. 1977. Improved growth in vitro colonies in human acute leukaemia with feeding culture method. Cancer Res. 37: 45954601.

Dosik, H. and Verma, R. S. 1980. New karyotypic abnormalities in a patient with multiple myeloma. Mammalian chromosome Newsletter 21: 15.

Elves, M. W. and Israels, M. C. G. 1963. Chromosomes and serum proteins: A linked abnormality. Brit. Med. J. 2: 1024-1026.

Gahrton, G., Friberg, K. and Zech, L. 1977. A new translocation involving three chromosomes in chronic myelocytic leukaemia, 46, XY, $\mathrm{t}(9 ; 11 ; 22)$. Cytogenet. Cell. Genet. 18: 75-81.

German, J. L., Biro, C. E. and Bearn, A. G. 1961. Chromosomal abnormalities in Waldenstrom's macroglobulinaemia. Lancet 2: 48.

Gurr, E. 1962. Staining: Practical and Theoretical. Baltimore, The Williams and Wilkins Co.

Hagemeijer, A., Scizzo, W., Smit, E.M.E. and Abels, J. 1961. Translocation (5p; 17q) in blast crisis of chronic leukaemia. Cytogenet. Cell Genet. 30: 205-210.

Hamerton, J. L. 1971. Cytological Techniques. Human Cytogenetics, Vol. 1. Academic Press Inc. N. Y. and London.

Kelsen, D. P., Gee, T. S. and Chaganti, R. S. K. 1979. Ph' chromosome positive chronic myelogenous leukaemia developing in a patient with acute lymphoblastic leukaemia. Cancer 43: 1782-1787.

Lewis, F. J. W., Fraser, I. L. and MacTaggart, M. 1963. An abnormal chromosomal pattern in myelomatosis. Lancet 2: 1013-1015.

Liang, W. and Rowley, J. D. 1978. $14 \mathrm{q}^{+}$marker chromosomes in multiple myeloma and plasmacell leukaemia. Lancet 1: 96. 
Olinici, C. D., Petrlov, L., Macaveii, I. and Olga, D. 1978. Different cell clones in bone marrow and spleen of a patient with chronic myelocytic leukaemia (CML) in blastic phase. Cancer 42: 2707-2709.

Pfeiffer, R. A., Kosenow, W. and Baumer, A. 1962. Chromosomenuntersuchungen an Blutzellen eines Patienten mit Makroglobulinamie Waldenstrom. Klin. Wochschr. 40: 342-344.

Wurster-Hill, D. H., McIntyre, O. R. and Cornwell, G. G. 1978. Chromosome studies in myelomatosis. Virchows Archiv, B. Cell Pathology 29: 93. 